\title{
Effect of deficit irrigation and reclaimed water on yield and quality of grapefruits at harvest and postharvest
}

\author{
Cristina Romero-Trigueros*, Margarita Parra, Jose M. Bayona, Pedro A. Nortes, \\ Juan J. Alarcón, Emilio Nicolás \\ Department of Irrigation, Centro de Edafología y Biología Aplicada del Segura, CEBAS-CSIC, P.O. Box 164, 30100, Murcia, Espinardo, Spain
}

\section{A R T I C L E I N F O}

\section{Article history:}

Received 1 July 2016

Received in revised form

28 April 2017

Accepted 1 May 2017

Available online 3 May 2017

\section{Keywords:}

Citrus

Cold storage

Crop load

Soluble solid content

Yield

\begin{abstract}
A B S T R A C T
The aim of our research was to discover the effects of the long-term irrigation with saline reclaimed (RW) and transfer (TW) water and different irrigation strategies: control (C) and regulated deficit irrigation (RDI) on yield and fruit quality of grapefruit at harvest and during cold storage. TW-RDI treatment decreased tree canopy (TC) and crop load, resulting in a 21\% reduction of fruit yield. Regarding fruit quality, RW notably decreased peel thickness at harvest (about 8\%); however, this difference was not remained during cold storage. Sugar/acid ratio was mainly increased by RDI, but also by RW, due to an important increase in soluble solid content (11\% of average value for TW-RDI, RW-C and RW-RDI). In addition, RDI combined with RW, significantly increased the number of fruits in small category 5 at the end of cold storage. Finally, neither ratio yield/TC nor irrigation water productivity were affected by any irrigation treatments.
\end{abstract}

(c) 2017 Elsevier Ltd. All rights reserved.

\section{Introduction}

Current climate change predictions indicate increases in the frequency and intensity of drought periods for Mediterranean areas (García-Galiano, Giménez, Martínez-Pérez, \& Giraldo-Osorio, 2015). In these regions, irrigation water is scarce and many orchards suffer from drought periods. In order to overcome this, the development of strategies to optimize water productivity is needed. A useful approach is regulated deficit irrigation (RDI), where water deficits are imposed during phenological periods least sensitive to water stress, with little or no impact on fruit yield and quality. In fact, RDI has been shown to improve water use efficiency and fruit quality in Citrus (e.g. García-Tejero et al., 2010), a crop with species of great economical relevance in the Mediterranean and worldwide.

Moreover, the use of non-conventional water sources such as

Abbreviations: C, control; EC, electrical conductivity; RDI, regulated deficit irrigation; RW, reclaimed water; SSC, soluble solid content; TA, titratable acidity; $\mathrm{TC}$, tree canopy volume; $\mathrm{TW}$, transfer water; $\mathrm{WP}_{\mathrm{i}}$, irrigation water productivity; Yield/TC, yield/tree canopy.

* Corresponding author. Present address: Departamento de Riego, Centro de Edafología y Biología Aplicada del Segura, CEBAS-CSIC. Campus Espinardo P.O. Box 164, 30100, Murcia, Espinardo, Spain.

E-mail address: cromero@cebas.csic.es (C. Romero-Trigueros). reclaimed water (RW) is also an alternative for farmers in these regions. On the one hand, RW can be beneficial to crops due to its high macronutrient concentration (Pedrero, Mounzer, Alarcón, Bayona, \& Nicolás-Nicolás, 2013), considering that an excess of them could be lost through leaching (Romero-Trigueros, Nortes, Alarcón, \& Nicolás, 2014). Besides, RW may imply risks to agriculture due to its higher salt concentration. Therefore, an inadequate management of irrigation with RW can exacerbate problems of salinization and soil degradation at the medium-long term, resulting in negative impacts on crop physiology, yield and fruit quality (Nicolás et al., 2016). The use of saline water decreases yield of mandarin trees due to the reduction of both fruit number and weight and it increases the juice soluble solid content (SSC) and titratable acidity (TA) (Navarro, Pérez-Pérez, Romero, \& Botía, 2010). Prior, Grieve, Bevington, and Slavich (2007) also reported that irrigation water with an electrical conductivity (EC) of $2.5 \mathrm{dS} \mathrm{m}^{-1}$ cause a reduction in yield of orange trees due to a decrease in fruit size.

The maintenance of fruit quality depends on storage conditions to a great extent (Fischer, 2000). However, environmental conditions and agronomic factors, such as the water source quality and irrigation strategies, also have a marked influence on fruit quality at postharvest (Fischer, 2000). Fruit quality at postharvest in Citrus managed through RDI has been rarely addressed (e.g. Conesa et al., 2014). Moreover, studies accounting for the effects of irrigation 
with RW on postharvest quality of Citrus have never been carried out.

The experiment reported here is the first one to evaluate of grapefruit quality after being irrigated with RW and RDI for eight years in the field. The aims of this study were to assess the effects of these irrigation strategies on fruit yield and quality at harvest and postharvest during cold storage for 31 days.

\section{Materials and methods}

\subsection{Site characterization and irrigation treatments}

The experiment was conducted during 2013-2015 period at a commercial Citrus orchard located at Molina de Segura, Region of Murcia $\left(38^{\circ} 07^{\prime} 18^{\prime \prime} \mathrm{N}, 1^{\circ} 13^{\prime} 15^{\prime \prime} \mathrm{W}\right)$. The experimental plot was cultivated with 9 year-old (since 2013) 'Star Ruby' grapefruit trees (Citrus paradisi Macf) grafted on Macrophylla rootstock spaced $6 \times 4 \mathrm{~m}$. Regular irrigation was scheduled on the basis of crop evapotranspiration $\left(\mathrm{ET}_{\mathrm{c}}\right.$ ) as described by Pedrero et al. (2015).

Beginning in 2007, two different water sources were used. The first one was pumped from the Tajo-Segura canal (transfer water,

Table 1

Physical and chemical parameters for both transfer water (TW) and reclaimed water (RW) in 2015.

\begin{tabular}{llll}
\hline Parameter & Units & TW & RW \\
\hline $\mathrm{EC}$ & $\mathrm{dS} \mathrm{m}{ }^{-1}$ & $1.00 \pm 0.01$ & $3.21 \pm 0.20$ \\
$\mathrm{pH}$ & & $8.41 \pm 0.09$ & $7.70 \pm 0.10$ \\
$\mathrm{Ca}$ & $\mathrm{meq} \cdot \mathrm{L}^{-1}$ & $1.99 \pm 0.10$ & $3.58 \pm 0.20$ \\
$\mathrm{Mg}$ & $\mathrm{meq} \cdot \mathrm{L}^{-1}$ & $1.58 \pm 0.10$ & $3.92 \pm 0.30$ \\
$\mathrm{~K}$ & $\mathrm{mg} \cdot \mathrm{L}^{-1}$ & $3.65 \pm 1.40$ & $38.94 \pm 1.40$ \\
$\mathrm{Na}$ & $\mathrm{meq} \cdot \mathrm{L}^{-1}$ & $1.86 \pm 0.20$ & $18.30 \pm 1.20$ \\
$\mathrm{~B}$ & $\mathrm{mg} \cdot \mathrm{L}^{-1}$ & $0.10 \pm 0.01$ & $0.66 \pm 0.04$ \\
$\mathrm{Cl}$ & $\mathrm{meq} \cdot \mathrm{L}^{-1}$ & $3.15 \pm 0.40$ & $20.10 \pm 3.01$ \\
$\mathrm{NO}_{3}^{-}$ & $\mathrm{mg} \cdot \mathrm{L}^{-1}$ & $7.70 \pm 3.60$ & $25.42 \pm 10.6$ \\
$\mathrm{PO}_{4}^{--}$ & $\mathrm{mg} \cdot \mathrm{L}^{-1}$ & $0.31 \pm 0.02$ & $1.73 \pm 0.70$ \\
$\mathrm{SO}_{4}^{--}$ & $\mathrm{meq} \cdot \mathrm{L}^{-1}$ & $5.90 \pm 0.50$ & $17.20 \pm 3.40$ \\
\hline
\end{tabular}

Values are averages \pm SE of 12 individual measurements taken throughout the crop cycle.
TW) and the second one was pumped from Molina de Segura tertiary wastewater treatment plant (reclaimed water, RW). The later showed high levels of salinity and $\mathrm{N}, \mathrm{P}$ and $\mathrm{K}$ (Table 1 ). Two irrigation treatments were established in the same year for each water source:

i) Control (C) irrigated to fully satisfy crop water requirements $\left(100 \% \mathrm{ET}_{\mathrm{c}}\right)$

ii) Regulated Deficit Irrigation (RDI) which received half the water amount applied to the $\mathrm{C}\left(50 \% \mathrm{ET}_{\mathrm{C}}\right)$ during the second stage of fruit development (from 26, July to 14 , September).

The total amounts of water applied to $C$ and RDI were 5938 and $5055 \mathrm{~m}^{3} \mathrm{ha}^{-1}$ in 2013, 6125 and $5010 \mathrm{~m}^{3} \mathrm{ha}^{-1}$ in 2014 and 5929 and $4883 \mathrm{~m}^{3} \mathrm{ha}^{-1}$ in 2015 , respectively (Fig. 1 ).

The experiment was laid out in randomised blocks with 4 replications. Each replicate consisted of 3 rows with 4 trees each. The 2 trees in the center of the middle rows were used for measurements and the rest acted as buffer rows.

\subsection{Vegetative growth, yield and fruit quality}

Eight trees per treatment were evaluated in 2013-2015 period to determine tree canopy volume (TC), crop load, yield, fruit weight, fruit diameter, specific weight calculated as fruit weight $\mathrm{x}$ fruit diameter $^{-1}$ and stem water potential $\left(\Psi_{s}\right)$. The TC was estimated from the height and diameter of the tree's foliage, considering the tree as a pyramid-shaped unit (Hutchinson, 1977). Besides, to evaluate yield efficiency the yield/TC ratio was calculated. $\Psi_{\mathrm{s}}$ was measured using a pressure chamber (model 3000; Soil Moisture Equipment Corp., California, USA) in leaves close to the trunk which were wrapped in aluminum foil at least $2 \mathrm{~h}$ before.

The irrigation water productivity $\left(\mathrm{WP}_{\mathrm{i}}\right)$ was calculated as the ratio between the annual yield $\left(\mathrm{kg} \cdot \mathrm{ha}^{-1}\right)$ and the applied water $\left(\mathrm{m}^{3} \cdot \mathrm{ha}^{-1}\right)$.

Fruits were harvested from 2013 to 2015 and quality parameters were determined in 40 fruits randomly selected (10 for each replicate) every year. Moreover, fruits from second harvest in 2015 were used for the postharvest study. Ninety fruits per treatment

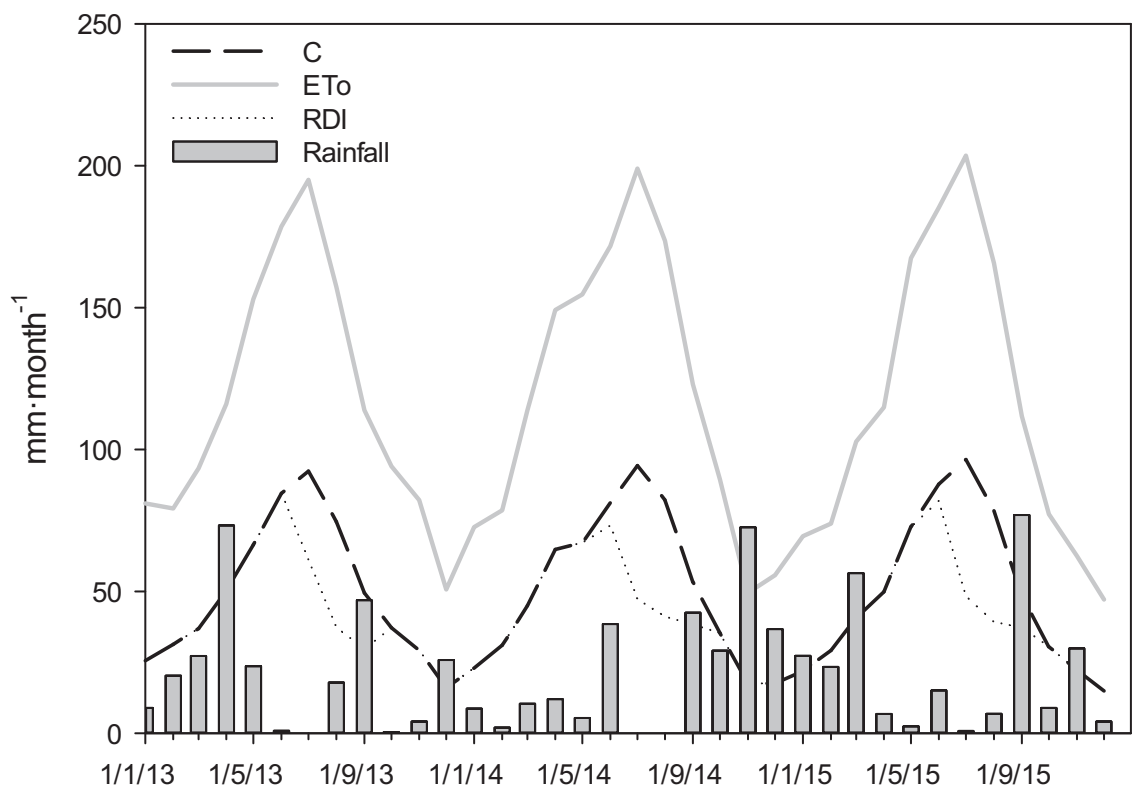

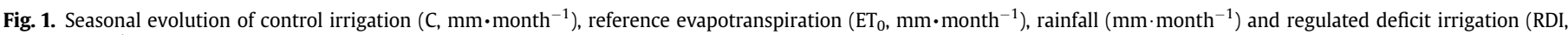
$\mathrm{mm} \cdot \mathrm{month}^{-1}$ ) in 2013, 2014 and 2015. 
were stored in darkness at $10{ }^{\circ} \mathrm{C}$ and $85 \%$ relative humidity for 31 days. Quality parameters were measured on fifty fruits per treatment at different times (0,10,17, 24 and 31 storage days). Fruit weight loss was determined at every sampling date in 10 marked fruits per treatment.

The quality parameters evaluated at harvest (2013-2015) and postharvest (2015) included peel thickness, color index, juice content, soluble solid content (SSC), titratable acidity (TA) and SSC/TA ratio. Peel thickness was determined using a digital caliper. Peel color was measured using a Minolta CR-300 colorimeter at two locations around fruit equatorial plane. Hunterlab parameters $L, a$ and $b$ were used, and color index was calculated as $(a \times 1000) /$ $(L \times b)$, where $L$ indicates lightness and $a$ and $b$ are the chromaticity coordinates (Jiménez-Cuesta, Cuquerella, \& Martínez-Jávega, 1981). Juice content was calculated as juice weight/fruit weight $\times 100$. SSC and TA were measured according to Nicolás et al. (2016). SSC/TA ratio was used for both an indication of fruit maturity at field or an indication of perception of taste by the consumer and expression of juice quality at postharvest. Finally, commercial categories were established for fruit of postharvest according to Codex Standards for grapefruit (Codex Stan 219, 1999).

A weighted analysis of variance (ANOVA; statistical software IBM SPSS Statistics v.21 for Windows) followed by Tukey's multiple comparison test $(\mathrm{P} \leq 0.05)$ were used for assessing differences among treatments. The data from Tables 2 and 3 were analyzed using a two-way ANOVA: firstly, with water source and water amount as main factors and, then, with treatment and year (2013, 2014 and 2015) as main factors. Weight loss percentages from Fig. 2A were analyzed with a two-way ANOVA for repeated measures. These percentage values were arscine-transformed before

Table 2

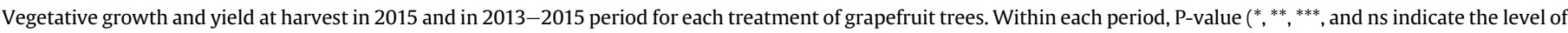

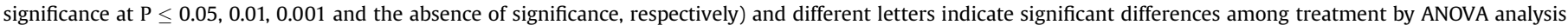
followed of Tukey's test $(\mathrm{P} \leq 0.05)$

\begin{tabular}{|c|c|c|c|c|c|c|c|c|c|}
\hline Period & & Treatment & TC & Crop load & Fruit weight & Fruit diameter & Yield & Yield/TC & $W P_{i}$ \\
\hline \multirow{9}{*}{2015} & & TW-C & $7.6 \mathrm{~b}$ & $614 b$ & $383.1 c$ & $104.8 b$ & $232.7 b$ & $30.7 a$ & $16.3 a$ \\
\hline & & TW-RDI & $6.0 \mathrm{a}$ & $276 a$ & $366.4 \mathrm{bc}$ & 102.3ab & 184.3a & $30.6 a$ & $15.5 a$ \\
\hline & & RW-C & $7.6 \mathrm{~b}$ & $771 b$ & 351.3ab & 101.6a & $244.4 b$ & $32.3 a$ & $17.1 \mathrm{a}$ \\
\hline & & RW-RDI & $6.0 \mathrm{a}$ & $742 b$ & $335.0 \mathrm{a}$ & $100.0 \mathrm{a}$ & $208.5 \mathrm{ab}$ & $34.9 \mathrm{a}$ & 17.6a \\
\hline & & SE & 0.6 & 58 & 9.9 & 1.1 & 19.0 & 3.9 & 1.5 \\
\hline & & P-value & $* *$ & $* * *$ & $* * *$ & $* * *$ & $* * *$ & ns & ns \\
\hline & \multirow{3}{*}{ Significance } & Water source (RW or TW) & 0.942 & 0.000 & 0.000 & 0.001 & 0.192 & 0.354 & 0.181 \\
\hline & & Water amount (C or RDI) & 0.000 & 0.000 & 0.022 & 0.012 & 0.004 & 0.051 & 0.864 \\
\hline & & Source $\mathrm{x}$ amount & 0.954 & 0.001 & 0.970 & 0.600 & 0.645 & 0.535 & 0.563 \\
\hline \multirow{9}{*}{ Average 2013-2015 } & \multirow{9}{*}{ Significance } & TW-C & $7.56 \mathrm{~b}$ & $645 b$ & $353.2 \mathrm{a}$ & $99.4 \mathrm{~b}$ & $216.6 b$ & $28.6 a$ & $15.0 \mathrm{a}$ \\
\hline & & TW-RDI & $5.6 a$ & $546 a$ & $342.7 \mathrm{a}$ & $97.4 \mathrm{a}$ & 191.0ab & $34.1 \mathrm{a}$ & $16.0 \mathrm{a}$ \\
\hline & & RW-C & $7.7 \mathrm{~b}$ & $675 b$ & $351.8 \mathrm{a}$ & $98.8 \mathrm{ab}$ & $215.6 b$ & $28.1 \mathrm{a}$ & $14.9 \mathrm{a}$ \\
\hline & & RW-RDI & $5.8 \mathrm{a}$ & 634ab & $345.0 \mathrm{a}$ & 98.0ab & $185.6 a$ & $31.8 \mathrm{a}$ & $15.6 a$ \\
\hline & & SE & 0.5 & 46 & 5.7 & 0.6 & 13.4 & 2.6 & 1.0 \\
\hline & & P-value & $* *$ & $*$ & ns & $* *$ & $*$ & ns & ns \\
\hline & & Water source (RW or TW) & 0.942 & 0.04 & 0.916 & 0.947 & 0.007 & 0.463 & 0.238 \\
\hline & & Water amount (C or RDI) & 0.000 & 0.080 & 0.036 & 0.002 & 0.739 & 0.049 & 0.720 \\
\hline & & Source $\mathrm{x}$ amount & 0.954 & 0.369 & 0.646 & 0.185 & 0.819 & 0.535 & 0.777 \\
\hline
\end{tabular}

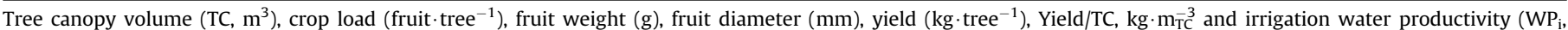

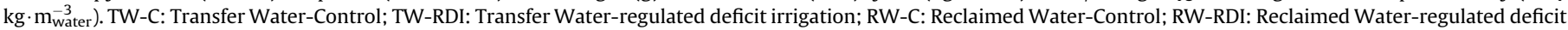
irrigation. Each point is the average of eight measurements performed in two inner trees per replicate. SE is average standard error for all treatments.

Table 3

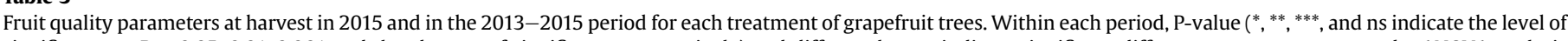

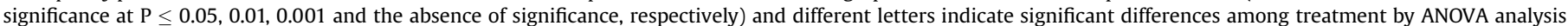
followed of Tukey's test $(\mathrm{P} \leq 0.05)$.

\begin{tabular}{|c|c|c|c|c|c|c|c|}
\hline Year & & Treatment & Peel thickness & Juice content & SSC & TA & SSC/TA ratio \\
\hline \multirow{9}{*}{2015} & & TW-C & $9.1 \pm 0.2 b$ & $46.9 \pm 0.4 \mathrm{ab}$ & $8.78 \pm 0.05 a$ & $1.87 \pm 0.02 \mathrm{a}$ & $4.70 \pm 0.08 a$ \\
\hline & & TW-RDI & $9.1 \pm 0.3 b$ & $45.7 \pm 0.5 a$ & $9.82 \pm 0.22 b$ & $1.99 \pm 0.06 a$ & $4.95 \pm 0.12 a$ \\
\hline & & RW-C & $9.0 \pm 0.2 \mathrm{ab}$ & $46.6 \pm 0.8 \mathrm{ab}$ & $9.73 \pm 0.12 b$ & $1.96 \pm 0.06 a$ & $5.01 \pm 0.21 a$ \\
\hline & & RW-RDI & $8.3 \pm 0.2 a$ & $48.9 \pm 0.5 b$ & $9.96 \pm 0.12 b$ & $1.96 \pm 0.03 a$ & $5.07 \pm 0.05 a$ \\
\hline & & SE & 2.3 & 3.3 & 5.9 & 1.87 & 2.0 \\
\hline & & P-value & ns & $* *$ & $* * *$ & ns & ns \\
\hline & \multirow{3}{*}{ Significance } & Water source (RW or TW) & 0.060 & 0.036 & 0.000 & 0.461 & 0.108 \\
\hline & & Water amount (C or RDI) & 0.187 & 0.476 & 0.000 & 0.186 & 0.235 \\
\hline & & Source $\mathrm{x}$ amount & 0.164 & 0.012 & 0.007 & 0.184 & 0.477 \\
\hline \multirow{9}{*}{ Average 2013-2015 } & \multirow{9}{*}{ Significance } & TW-C & $8.9 \pm 0.1 b$ & $45.8 \pm 0.5 a$ & $8.49 \pm 0.12 a$ & $1.78 \pm 0.02 \mathrm{a}$ & $4.78 \pm 0.07 a$ \\
\hline & & TW-RDI & $8.5 \pm 0.2 \mathrm{ab}$ & $45.3 \pm 0.6 a$ & $9.58 \pm 0.12 b$ & $1.86 \pm 0.05 a b$ & $5.22 \pm 0.08 c$ \\
\hline & & RW-C & $8.3 \pm 0.1 \mathrm{a}$ & $45.9 \pm 0.6 a$ & $9.27 \pm 0.11 b$ & $1.91 \pm 0.02 b$ & $4.86 \pm 0.07 a b$ \\
\hline & & RW-RDI & $8.2 \pm 0.1 \mathrm{a}$ & $46.8 \pm 0.5 a$ & $9.30 \pm 0.18 b$ & $1.85 \pm 0.04 a b$ & $5.05 \pm 0.06 b c$ \\
\hline & & SE & 3.4 & 1.9 & 5.7 & 2.7 & 4.5 \\
\hline & & P-value & $* *$ & ns & $* * *$ & ns & $* * *$ \\
\hline & & Water source (RW or TW) & 0.003 & 0.153 & 0.071 & 0.093 & 0.521 \\
\hline & & Water amount (C or RDI) & 0.104 & 0.665 & 0.000 & 0.971 & 0.000 \\
\hline & & Source $\mathrm{x}$ amount & 0.296 & 0.201 & 0.000 & 0.063 & 0.071 \\
\hline
\end{tabular}

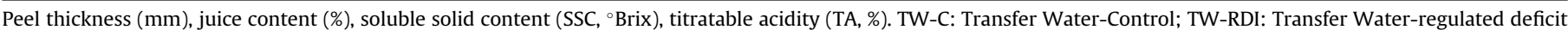

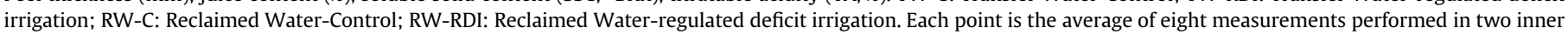
trees per replicate. SE is average standard error for all treatments. 


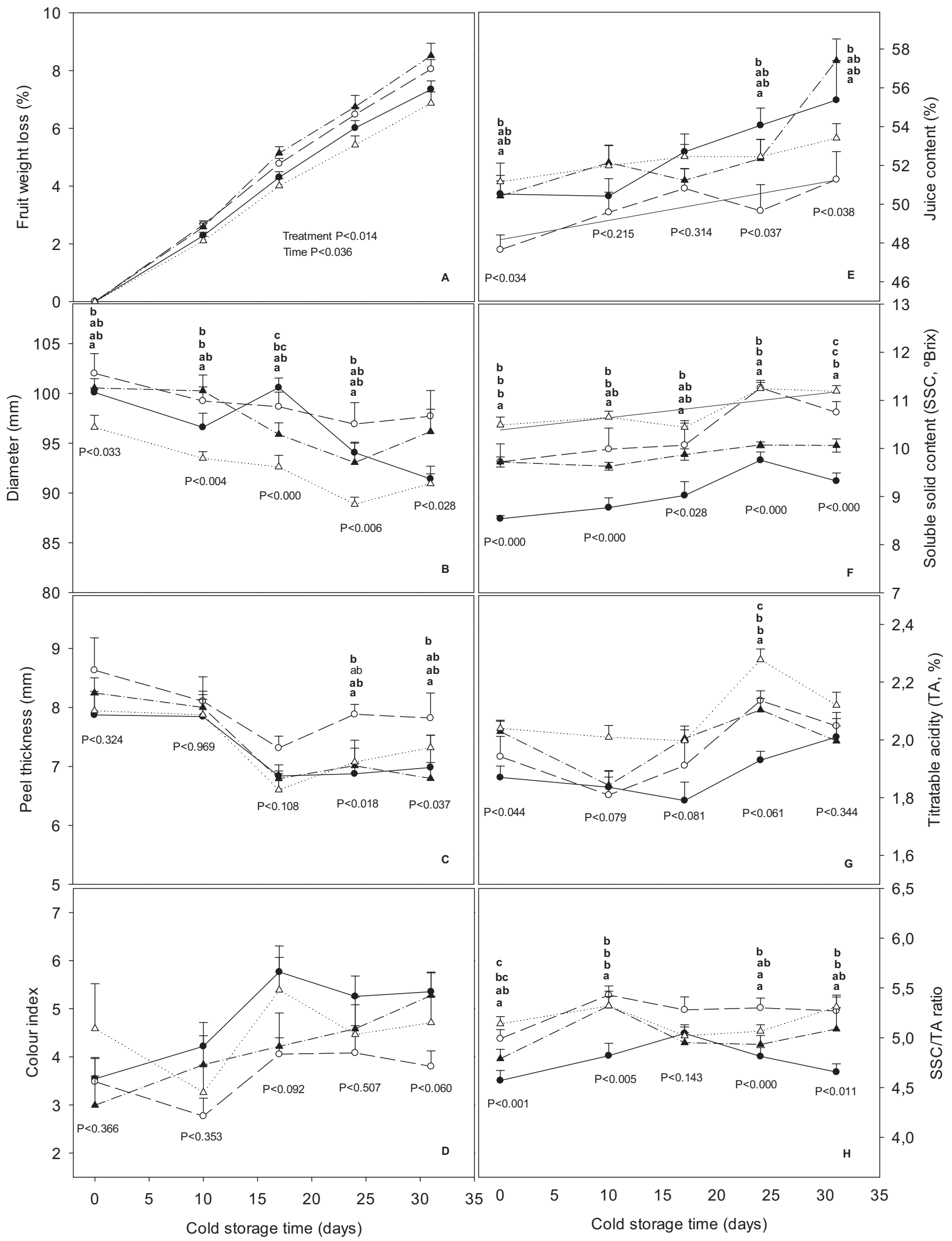


Table 4

Relationships between quality parameters and time of postharvest.

\begin{tabular}{|c|c|c|c|c|c|c|c|c|c|c|c|c|c|c|c|c|}
\hline & \multicolumn{2}{|c|}{$\begin{array}{l}\text { Fruit weight } \\
\text { loss }\end{array}$} & \multicolumn{2}{|c|}{$\begin{array}{l}\text { Fruit } \\
\text { diameter }\end{array}$} & \multicolumn{2}{|c|}{$\begin{array}{l}\text { Peel } \\
\text { thickness }\end{array}$} & \multicolumn{2}{|c|}{ Color Index } & \multicolumn{2}{|c|}{ Juice content } & \multicolumn{2}{|c|}{ SSC } & \multicolumn{2}{|c|}{ TA } & \multicolumn{2}{|c|}{ SSC/TA ratio } \\
\hline & $\mathrm{s}$ & $\mathrm{R} 2$ & s & $\mathrm{R} 2$ & $\mathrm{~s}$ & $\mathrm{R} 2$ & $\mathrm{~S}$ & $\mathrm{R} 2$ & s & $\mathrm{R} 2$ & $\mathrm{~s}$ & $\mathrm{R} 2$ & $\mathrm{~s}$ & $\mathrm{R} 2$ & $\mathrm{~s}$ & $\mathrm{R} 2$ \\
\hline TW-C & + & $0.99^{* * *}$ & - & 0.63 & - & 0.68 & + & 0.68 & + & $0.90^{* *}$ & + & $0.72 *$ & + & 0.41 & + & 0.04 \\
\hline TW-RDI & + & $0.99^{* * *}$ & - & $0.83^{*}$ & - & 0.42 & + & 0.29 & + & $0.72^{*}$ & + & 0.68 & + & 0.40 & + & 0.24 \\
\hline RW-C & + & $0.99^{* * *}$ & - & 0.63 & - & $0.78^{*}$ & + & $0.99 * * *$ & + & $0.90^{* *}$ & + & $0.76^{*}$ & + & 0.08 & + & 0.05 \\
\hline RW-RDI & + & $0.99 * * *$ & - & $0.79 *$ & - & 0.35 & + & 0.07 & + & $0.93^{* *}$ & + & 0.64 & + & 0.31 & + & 0.01 \\
\hline
\end{tabular}

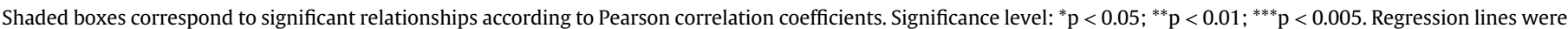

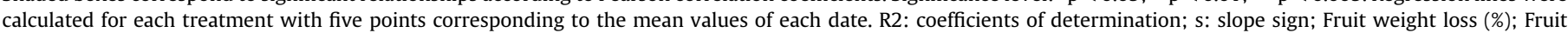

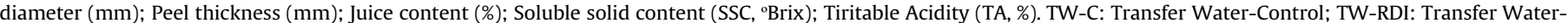
regulated deficit irrigation; RW-C: Reclaimed Water-Control; RW-RDI: Reclaimed Water-regulated deficit irrigation.

statistical analysis. The rest of quality parameters from Fig. 2 were analyzed with a two-way ANOVA to examined the interaction between treatments and time. Linear regressions among quality parameters and time were calculated to indicate whether a certain parameter increased or decreased during storage. Pearson correlation coefficients were used to assess the significance of these relationships. All statistical analyses were performed using SPSS (vers. 23.0 for Win-dows, SPSS Inc., Chicago, IL, USA).

\section{Results and discussion}

\subsection{Fruit yield and quality at harvest}

Average data of the 2013-2015 period are shown in a set to observed a general medium-term behavior since interactions treatments with year for different parameters are non-significant. Regardless water source, TC was reduced by RDI in 2015 and during the 2013-2015 seasons (Table 2), in agreement with other studies carried out in Citrus (e.g. Pedrero, Maestre-Valero, Mounzer, Alarcón, \& Nicolás, 2014). Crop load was also decreased by RDI: TW-RDI in 2015 and both TW-RDI and RW-RDI during 2013-2015 seasons, as Pedrero et al. (2013) for mandarin and Pérez-Pérez, García-Sánchez, Robles, \& Botía (2015) for grapefruit observed. Fruit weight was reduced (4, 9 and $14 \%$ for TW-RDI, RW-C and RWRDI, respectively) by water restriction and the use of saline water, and mainly by their combination in 2015 (Table 2). However, although it presented the same tendency, no significant differences in the average value of 2013-2015 were detected. Fruit diameter was also reduced in RW treatments for 2015 and in TW-RDI for 2013-2015 period, coinciding with the lowest values of specific weight; this might be caused by a less dry matter accumulation (Cohen \& Goell, 1998) or dehydration in stressed grapefruit.

RDI or irrigation with saline RW in citrus is generally associated to a reduction in the TC and crop load and/or the fruit yield (GarcíaTejero et al., 2010; Pedrero et al., 2013; Pérez-Pérez et al., 2015). In this case, a reduction of the TC and crop load led to lower yield in RDI treatments, as reported by Pérez-Pérez, Robles, and Botía (2014), significantly on TW-RDI in 2015 (21\% decrease) and on RW-RDI during 2013-2015 (14\% reduction). This could be confirmed by the ratio yield/TC (Nicolás et al., 2016), however, in this experiment it was not significantly different in any treatment. Moreover, $\mathrm{WP}_{\mathrm{i}}$ was also not affected by irrigation treatments, despite the water savings by RDI, as in Nicolás et al. (2016). Therefore, RDI was not a more efficient system than Control because the reduction in canopy growth affected yield proportionally.

Regarding fruit quality parameters (Table 3), a decreasing trend in peel thickness was observed in RW with respect to TW treatments in both 2015 and 2013-2015 periods, mainly in RW-RDI (a reduction of 9 and 8\% in 2015 and 2013-2015 period, respectively). Juice content was lower in TW-RDI than in the other treatments in 2015 , because such treatment presented the lowest values of $\Psi_{\mathrm{s}}$ (annual average value for TW-C, TW-RDI, RW-C and RWRDI: $-1.21,-1.43,-1.27$ and $-1.39 \mathrm{MPa}$, respectively) but no significant differences were detected for the 2013-2015 seasons although there were differences in $\Psi_{\mathrm{s}}$ (data not shown). Salinity and water stress increase the SSC and TA in Citrus fruits, thereby improving the internal fruit quality as reported by Navarro et al. (2010). In our experiment, SSC/TA ratio did not show differences in 2015 despite the significant increase in juice SSC on trees with water and/or salt stress $(12,11$ and $13 \%$ for TW-RDI, RW-C and RW$\mathrm{RDI}$, respectively, in relation to TW-C). However, SSC/TA ratio significantly increased in TW-RDI (8\%), RW-C (2\%) and RW-RDI (5\%) for 2013-2015 due to increases in SSC were higher (13, 9 and $10 \%$ for TW-RDI, RW-C and RW-RDI, respectively, in relation to TW-C) than variations in TA (4,7 and $4 \%$ for TW-RDI, RW-C and RW-RDI, respectively, in relation to $\mathrm{TW}-\mathrm{C}$ ), suggesting that harvest might be more precocious if fruit diameter is adequate. Otherwise, SSC is also used to set the price, so an increase in SSC can be more valuable than any anticipated harvest. In general, our results agree with those presented by Pérez-Pérez et al. (2014, 2015), who reported i) a reduction in juice content by RDI, as in 2015 , due to dehydration processes or internal changes in fruit structure and ii) an increase in SSC (under saline water) and in TA (under RDI and saline water). However, Pedrero et al. (2015) reported no differences in SSC/TA ratio for the same orchard during 2008-2010; this is because the measurements were taken at the first 3 years of establishment of RDI and RW. Besides, fruit quality often is affected by crop load, therefore, it would be necessary to have similar crop loads in both periods to really compare fruit quality. Pérez-Pérez et al. (2014) found an increase in peel thickness for grapefruit irrigated with saline water, in contrast with our results. This might be explained by the different rootstock used.

\subsection{Fruit quality at postharvest}

The data shown in Fig. 2 are the result of the combined effect of field treatments (RW and RDI) and cold storage, except for fruit

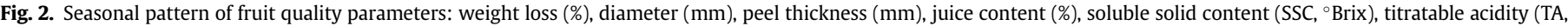

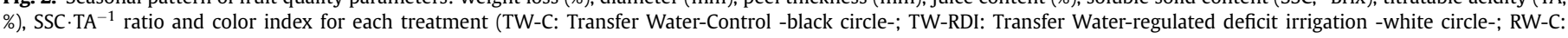

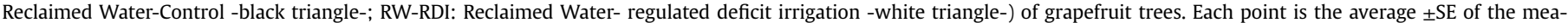

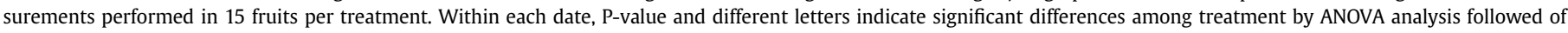
Tukey's test. In Fig. 2A, p-value corresponds to two-way ANOVA for repeated measures. 


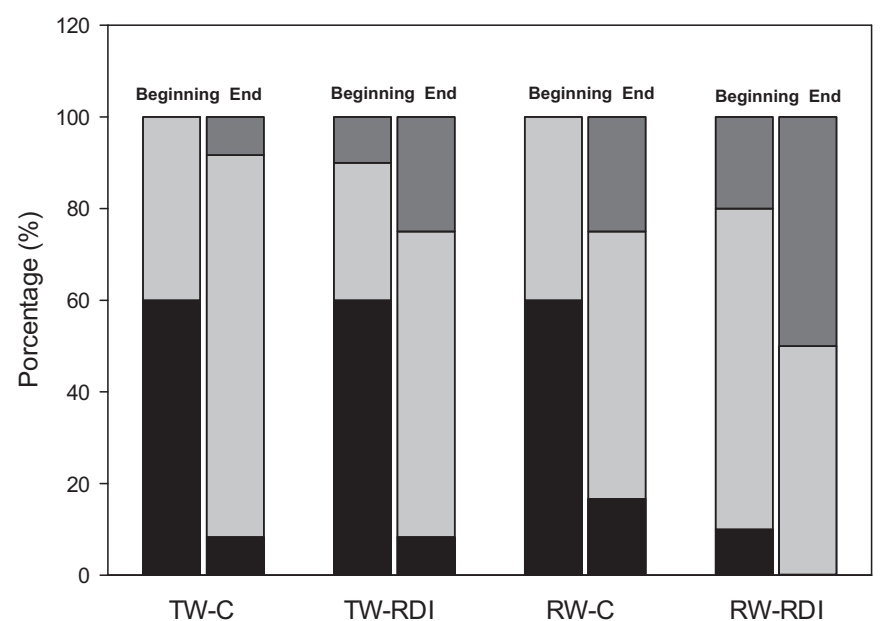

Fig. 3. Percentage of fruit size category for each treatment (TW-C: Transfer WaterControl; TW-RDI: Transfer Water-regulated deficit irrigation; RW-C: Reclaimed Water-Control; RW-RDI: Reclaimed Water-regulated deficit irrigation) at the beginning and the end of cold storage. Fruit diameters 100-120 (black), 93-100 (light grey) and 84-93 (grey) $\mathrm{mm}$ correspond to categories 3, 4 and 5, respectively. The words "Beginning" and "End" above the bars means at the beginning and at the end of storage.

weight loss which was expressed in percent of initial weight, cancelling any differences in due to field conditions. There was not a statistically significant interaction between the effects of treatment and time on quality parameters of Fig. 2 .

At the beginning of postharvest ( 0 storage day), no significant differences in peel thickness, color index and TA were observed among treatments (Fig. 2).

Throughout the cold storage period, fruit weight loss was significantly different between treatments (being greater in RW-C and lower in RW-RDI) and, in addition, it was also significantly different across time (p-value: 0.036, Fig. 2A). Fruit diameter decreased during storage in all treatments (Table 4), as expected. RW-RDI showed significantly lower values than the rest of the treatments from the beginning of storage (Fig. 2B); this was related with the lower fruit weight loss found in RW-RDI. Peel thickness decreased similarly in all treatments throughout the storage; therefore, one of the causes of weight loss could be that. Besides, the transpiration occurs in a greater proportion in the skin of the fruit than in the pulp as reported Liu, Shi, \& Langrish (2006) and Yapo (2009). In contrast with what occurred at harvest, RW treatments did not show significant differences respect TW treatments, and at the end of storage TW-RDI showed the highest values.

On the contrary, color index showed a tendency to increase during storage, mainly in Control treatments (Table 4 and Fig. 2D). The low temperature during storage probably resulted in a decrease in the chlorophyll/carotenoid ratio of the flavedo because chlorophyll was degraded over time (Power, Legar, \& Shervin, 1997). Juice content also increased during storage (Table 4 and Fig. 2E), since it is based on fruit weight; TW-RDI showed significantly lower values than the rest of the treatments, as at harvest.

Moreover, despite that grapefruit is a non-climacteric fruit, SSC increased during postharvest and it was probably due to a concentration effect by weight loss (Table 4 and Fig. 2F). TA, conversely, did not show a clear trend over time (Table 4 and Fig. 2G). Finally, SSC/TA ratio also did not have an evident trend through the storage (Table 4). However, last day of the postharvest it was enhanced by water restriction, although also by the use of RW and their combination due to higher SSC values, increasing the differences already observed between treatments at harvest and 0 storage day
(Fig. 2H). This result is important since grapefruit juices are produced by industries all over the world due to the preference of consumers based on its taste (La Cava \& Sgroppo, 2015). A positive linear correlation between SSC and preharvest water deficit was found by Castel and Buj (1990) for orange and Conesa et al. (2014) for mandarin.

Moreover, at 0 day of storage, water quality did not affect fruit size $[60 \%$ category $3(100-119 \mathrm{~mm})$ and $40 \%$ category 4 (93-100 mm) in both TW-C and RW-C]. However, water restriction resulted in a smaller fruit size [10 and $20 \%$ of category 5 (84-93 mm) fruits for TW-RDI and RW-RDI, respectively] (Fig. 3). At the end of storage, as expected, all treatments decreased the percentage of category 3 fruits and increased those of categories 4 and 5; mainly TW-RDI and RW-RDI which increased category 5 by 20 and $30 \%$, respectively.

To sum up, both RW and RDI strategies are increasingly needed in semi-arid areas and there is still a lack of knowledge of their long-term effects. The novelty of this study lies in the evaluation of grapefruit quality after being irrigated with RW and RDI for 8 years under field conditions. The findings of this study suggest that tree canopy, crop load and, therefore, yield were decreased by RDI. However, RW did not affect yield although it decreased slightly fruit diameter. In spite of the affected parameters mentioned above, neither yield/TC ratio nor WPi was reduced, despite the water savings. When RW was combined with RDI the number of fruits of small category $\left(n^{\circ} 5\right)$ at the end of postharvest was increased. Finally, both RDI and RW increased SSC values, improving the fruit taste.

\section{Acknowledgements}

This study was supported by two CICYT projects (AGL201017553 and AGL2013-49047-C2- 515 2-R) projects and SENECA-Excelencia Científica (19903/GERM/15).

\section{References}

Castel, J. R., \& Buj, A. (1990). Response of Salustiana'oranges to high frequency deficit irrigation. Irrigation Science Jorunal, 11, 121-127.

Codex Stan-219. (1999). Emd, 2-2005. www.fao.org/input/.../standards/345/CXS 219e.pdf [01/01/216].

Cohen, A., \& Goell, A. (1998). Fruit growth and dry matter accumulation in grapefruit during periods of water withholding and after reirrigation. Australian Journal Plant Physiology, 15, 633-639.

Conesa, M. R., García-Salinas, M. D., de la Rosa, J. M., Fernández-Trujillo, J. P. Domingo, R., \& Pérez-Pastor, A. (2014). Effects of deficit irrigation applied during fruit growth period of late mandarin trees on harvest quality, cold storage and subsequent shelf-life. Scientia Horticulturae, 165, 344-351.

Fischer, G. (2000). (Effects of pre-harvest conditions on post-harvest quality of fruits). [Efectos de las condiciones en precosecha sobre la calidad poscosecha de los frutos]. Comalfi, 27(1-2), 39-50.

García-Galiano, S. G., Giménez, P. O., Martínez-Pérez, J. A., \& Giraldo-Osorio, J. D. (2015). Improving evaluation of climate change impacts on the water cycle by remote sensing ET-retrieval. Remote Sensing and GIS for Hydrology and Water Resources, 368, 239-244.

García-Tejero, I. Jiménez-Bocanegra, J. A Martínez, G, Romero, R. DuránZuazo, V. H., \& Muriel-Fernández, J. L. (2010). Positive impact of regulated deficit irrigation on yield and fruit quality in a commercial citrus orchard. Agricultural Water Management, 97, 614-622.

Hutchinson, D. J. (1977). Influence of rootstock on the performance of "Valencia" sweet orange. Proceedings of the International Society Citriculture Congress, 2 , $523-525$.

Jiménez- Cuesta, M., Cuquerella, J. \& Martínez-Jávega, J. (1981). Determination of a color index for citrus fruit degreening. Proceedings of the International Society Citriculture Congress, 2, 750-753.

La Cava, E. L. M., \& Sgroppo, S. C. (2015). Evolution during refrigerated storage of bioactive compounds and quality characteristics of grapefruit [Citrus paradisi (Macf.)] juice treated with UV-C light. LWT-food Science and Techology, 63(2), 1325-1333.

Liu, Y., Shi, J., \& Langrish, T. (2006). Water-based extraction of pectin from flavedo and albedo of orange peels. Chemical Engineering Journal, 120(3), 203-209.

Navarro, J. M., Pérez-Pérez, J. G., Romero, P., \& Botía, P. (2010). Analysis of the changes in quality in mandarin fruit, produced by deficit irrigation treatments. 
Food Chemical, 119, 1591-1596.

Nicolás, E., Alarcón, J. J., Mounzer, O., Pedrero, F., Nortes, P. A., Alcobendas, R., \& Maestre-Valero, J. F. (2016). Long-term physiological and agronomic responses of mandarin trees to irrigation with saline reclaimed water. Agricultural Water Management, 166, 1-8.

Pedrero, F., Maestre-Valero, J. F., Mounzer, O., Alarcón, J. J., \& Nicolás, E. (2014). Physiological and agronomic mandarin trees performance under saline reclaimed water combined with regulated deficit irrigation. Agricultural Water Management, 146, 228-237.

Pedrero, F., Maestre-Valero, J. F., Mounzer, O., Nortes, P. A., Alcobendas, R., RomeroTrigueros, C., \& Nicolás, E. (2015). Response of young 'Star Ruby’ grapefruit trees to regulated deficit irrigation with saline reclaimed water. Agricultural Water Management, 158, 51-60.

Pedrero, F., Mounzer, O., Alarcón, J. J., Bayona, J. M., \& Nicolás-Nicolás, E. (2013). The viability of irrigating mandarin trees with saline reclaimed water in a semi-aric Mediterranean region: A preliminary assessment. Irrigation Science, 31(4), 759-768.

Pérez-Pérez, J. G., García-Sánchez, F., Robles, J. M., \& Botía, P. (2015). 'Star Ruby’ grapefruit and 'Clemenules' mandarin trees show different physiological and agronomic responses to irrigation with saline water. Irrigation Science, 33(3), 191-204. http://dx.doi.org/10.1007/s00271-014-0459-8.

Pérez-Pérez, J. G., Robles, J. M., \& Botía, P. (2014). Effects of deficit irrigation in different fruit growth stages on 'Star Ruby' grapefruit trees in semi-arid conditions. Agricultural Water Management, 133, 44-54.

Power, J. P., Legar, K., \& Shervin, A. (1997). Parameters relating to citrus chilling sensitivity. Citrus Journal, 7(5), 22-24.

Prior, L. D., Grieve, A. M., Bevington, K. B., \& Slavich, P. G. (2007). Long-term effects of saline irrigation water on valencia orange trees: Relationships between growth and yield, and salt levels in soil and leaves. Australian Journal of Agricultural Research, 58(4), 349-358.

Romero-Trigueros, C., Nortes, P. A., Alarcón, J. J., \& Nicolás, E. (2014). Determination of ${ }^{15} \mathrm{~N}$ stable isotope natural abundances for assessing the use of saline reclaimed water in grapefruit. Environmental Engineering and Management Journal, 13(10), 2525-2530.

Yapo, B. M. (2009). Pectin quantity, composition and physicochemical behavior as influenced by the purification process. Food Research International, 42(8), 1197-1202. 